\title{
Working as a doctor in Australia
}

\author{
Helen Jones freelance journalist \\ London, UK
}

With its promise of sun and a laidback lifestyle, Australia has long been a popular destination for UK trained doctors looking for a temporary or permanent move overseas. Getting a job there, however, has just become more difficult.

In its 2019 budget, the Australian government outlined plans to cut the number of overseas trained doctors entering Australia to work in primary healthcare by about $10 \%$-around 200 people annually-over the next four years. The government says it is a gradual process and will provide opportunities for the growing number of Australian trained medical graduates. Overseas trained doctors will be directed to "areas of workforce need," which means rural and remote communities.

That said, there are still plenty of opportunities available and, while more junior hospital positions may be filled within Australia, senior and specialised staff are in particular demand.

\section{What roles are available?}

GPs are in demand in rural areas although you may have to become adept at dealing with snakebites and tropical diseases. Psychiatrists of all types are highly sought after, as are specialists in obstetrics and gynaecology and radiologists. Emergency doctors are also needed. Emergency medicine is different in Australia as more procedures and investigations are carried out by emergency doctors than by specialists.

\section{Where are jobs available?}

There are jobs available across Australia from remote regions to working with indigenous communities to working in the big cities. Competition is greatest in Melbourne and Sydney, but recruitment agencies say that candidates may want to consider their suburban fringes or other locations such as Adelaide or Perth, for example, which are attractive cities with living costs around 20\% cheaper than Sydney.

\section{What's it like being a doctor in Australia?}

Doctors in Australia generally work fewer hours than in the UK-usually between 35 and 38 hours a week depending on seniority and specialism. Typically, hours worked beyond that will be considered overtime and will attract after hours pay, usually double time.

Recruitment agencies say that GPs in Australia can expect to earn around AUD\$240 000 ( $£ 130$ 893) and up to AUD\$380 000 in rural areas through a combination of salary, allowances, and bonuses. With after hours pay this can rise to about AUD\$400 000 .

\section{How do I find a job?}

There are three ways to find a job in Australia-through state health board job recruitment websites such as NSW Health, Queensland Health, and WA Health; directly applying to hospitals; or through medical recruitment agencies.

It can be a lengthy and complex process and can take 12 months between applying for a role and starting it. Many applicants choose to go through recruitment agencies which can offer guidance on finding the right job and getting through the various bureaucratic hoops.

Job interviews are carried out by Skype or by phone, although senior consultants may be flown out for face to face interviews. You will be required to provide references, complete a health questionnaire, and undergo a criminal record check.

\section{What are recruiters looking for?}

As well as the appropriate skills, Paul Rosengrave, general manager of Triple0 Medical Recruitment says applicants need the right attitude. "Often people are enthusiastic about making the move but become less keen over time because it can be a lengthy process. And if you have a family, they have to be involved. Sometimes we get half way through the process and then find out that the spouse isn't keen or the kids haven't been informed of the decision," he says.

\section{The paperwork}

Once you have an offer you are required to register with the Australian Medical Council, which approves General Medical Council accredited medical schools as competent for registration in Australia. You will also need to register with the Australian Health Practitioner Registration Authority which manages the registration process for the Medical Board of Australia (the Australian equivalent of the GMC).

To maintain a licence to practise in the UK, doctors need to be revalidated every five years by the GMC. If you are not practising in the UK, you can relinquish your licence while remaining on the GMC register. This avoids the need to revalidate and you pay a reduced fee while maintaining good standing with the GMC during that period.

Unless you have an Australian passport, you will need a visa to work there. The application process entails paperwork to be completed by your Australian employer and by you. It is complicated and many applicants are guided by an immigration 
agency or recruitment company. You can find out more about temporary and permanent visas at the Australian Department of Health's Doctor Connect website (www.doctorconnect.gov. $\mathrm{au})$.

\section{Useful contacts}

Australian Health Practitioner Regulation Agency: www.ahpra.gov.au Australian Medical Council: www.ahpra.gov.au NSW Health: www.health.nsw.gov.au/careers/Pages/default.aspx Queensland Health: www.health.qld.gov.au/employment/job-search WA Health: https://ww2.health.wa.gov.au 